\title{
Combination technique using patchwork and partial softening to determine the collision toughness and intrusion prevention in side crash simulation
}

Min Sik Lee ( $\nabla$ minsik2@pusan.ac.kr)

Pusan National University https://orcid.org/0000-0003-0184-5606

Chul Kyu Jin

Ok Dong Lim

Jun Ho Suh

\section{Research Article}

Keywords: Center pillar, Side crash simulation, Partial softening, Patchwork, Energy distribution

Posted Date: April 7th, 2022

DOI: https://doi.org/10.21203/rs.3.rs-1307324/v2

License: (c) (1) This work is licensed under a Creative Commons Attribution 4.0 International License.

Read Full License 


\title{
Combination technique using patchwork and partial softening to determine the collision toughness and intrusion prevention in side crash simulation
}

\author{
Min Sik Lee ${ }^{1, *} \cdot$ Chul Kyu Jin ${ }^{2} \cdot$ Ok Dong $\operatorname{Lim}^{3} \cdot$ Jun Ho Suh ${ }^{1, *}$ \\ ${ }^{1}$ School of Mechanical Engineering, Pusan National University, 30 Jangjeon-dong, Geumjeong-gu, \\ Busan, Republic of Korea. \\ ${ }^{2}$ School of Mechanical Engineering, Kyungnam University, Kyungnamdaehak-ro 7, Masanhappo-gu, \\ Changwon-si, Republic of Korea. \\ ${ }^{3}$ Autogen Co, Ltd, 2611-1 Jeongwang-dong, Siheung-si, Gyeonggi-do, Republic of Korea. \\ *corresponding email: minsik2@pusan.ac.kr, junhosuh@pusan.ac.kr
}

\begin{abstract}
Various techniques have been applied to center pillar to enhance collision characteristics during side crash. Among these techniques, the patchwork (PW) was welded to center pillar to strengthen the stiffness and partial softening (PS) was applied to provide ductility. Side crash test was conducted by Insurance Institute for Highway Safety (IIHS) to evaluate collision resistance. But it is hard to evaluate collision toughness and energy distribution flow for each automobile component. In this study, the side crash simulation was performed along with IIHS instruction. The effect of Hot Press Forming (HPF) center pillar with the combination techniques of PW and PS on collision toughness and energy distribution flow was investigated. As a result, the role of PW and PS techniques were verified during side crash. The strain energy and intrusion displacement by PW were improved 10, $7.5 \%$ respectively and the plastic deformation energy and intrusion displacement by PS were improved $10 \%$. When PW and PS were applied to the HPF center pillar simultaneously, the synergy effect of PW and PS occurred.
\end{abstract}

\section{Keywords}

Center pillar · Side crash simulation $\cdot$ Partial softening $\cdot$ Patchwork $\cdot$ Energy distribution 


\section{Introduction}

Due to demanding global environmental concern, the automobile industry has become increasingly interested in fuel efficiency and the weight reduction. As the demand for the technological development to achieve high performance and high fuel efficiency increases, the research on applying Advanced High Strength Steel (AHSS) to automobile components has progressed [1-4].

To enhance stiffness and strength of automobile component, Hot Press Forming (HPF) process has been introduced. In the HPF, the blank is heated to a high temperature to create an austenitic phase and then cooled rapidly in the forming dies to form martensite phase $[5,6]$.

However, hot stamped parts are used restrictively in automobile components requiring collision absorption because of their low elongation. For example, in the case of a side crash, B-pillar, which was called as center pillar, is the one of the important automobile components for passenger's safety. During the side crash impact, the center pillar needs the ductility to absorb the collision energy and the stiffness to improve intrusion resistance. There much research on center pillar with alternative materials [7-9] or post tempering process to obtain tailor properties $[10,11]$.

Nowadays, because of productivity and manufacturing cost, the patchwork (PW) and partial softening (PS) technique were famous and used as effective applications for center pillar to improve collision characteristics in the automobile industry.

To improve intrusion resistance with increasing stiffness of automobile component, the PW was attached to a center pillar to achieve reinforced structural stiffness. The formality of laser welded patchwork blank was investigated by Lamprecht and Geiger $[12,13]$. The spot weld conditions to attach PW to HPF parts was optimized by Ahmad et al. [14]. Chengxi et al. [15] studied to improve mechanical properties of B pillar with PW and predict the temperature distribution through FE simulation.

To improve energy absorption with increasing ductility of automobile component, PS have been performed. To obtain tailored mechanical properties of 22MnB5, Banik et al. [16] controlled die quenching speed. The damage value and tailored temperature with forming limit diagram were evaluated by Ota et al. 
[17]. Bok et al. [18] performed simulation to predict the microstructure and mechanical properties of B pillar and compared to experiment result. Kim et al. [19] manufactured the B pillar using partial strengthening method with minimal shape change. Recently, M. S. Lee et al. [20] manufactured the HPF center pillar with PW and PS by controlling the cooling rate and conducted drop weight experiment experimentally and numerically.

However, above researches were just manufacture process and it is hard to evaluate collision toughness and energy distribution flow for each automobile component. There are few research on side crash test to evaluate effect of PW and PS on collision toughness and energy distributions. In this study, the PW and PS techniques were applied to HPF center pillar to improve stiffness and ductility and drop weight test was conducted and compared to simulation for confirming the validation of results. Then, the effect of combination technique using PW and PS on energy distribution flows and intrusion resistance were investigated through side crash simulation along with IIHS instruction.

\section{Experiment and simulation}

\subsection{Materials}

Figure 1 (a) shows that the function of center pillar during a side crash. Generally, the HPF center pillar has a low elongation with less than $5 \%$ so that collision toughness is not satisfied. In addition, the stiffness of center pillar at top region is not sufficient against intrusion resistance. The PS technique provide the ductility to HPF center pillar and the PW strengthen the stiffness of HPF center pillar to improve collision characteristics such as energy absorption and intrusion resistance.

In this study, 22MnB5 boron steel sheet was used for the HPF center pillar and PW. The PS region was controlled by cartridge heater during manufacturing HPF center pillar ${ }^{20}$. Table 1 shows Material properties of 22MnB5 (HPF) and 22MnB5 (PS). The thickness of HPF center pillar and PW were both $1.2 \mathrm{~mm}$. To evaluate the effect of PW and PS on energy distribution and intrusion resistance, the side crash simulation was performed with four kinds of the center pillar was used as show in Fig. 1 (b). 


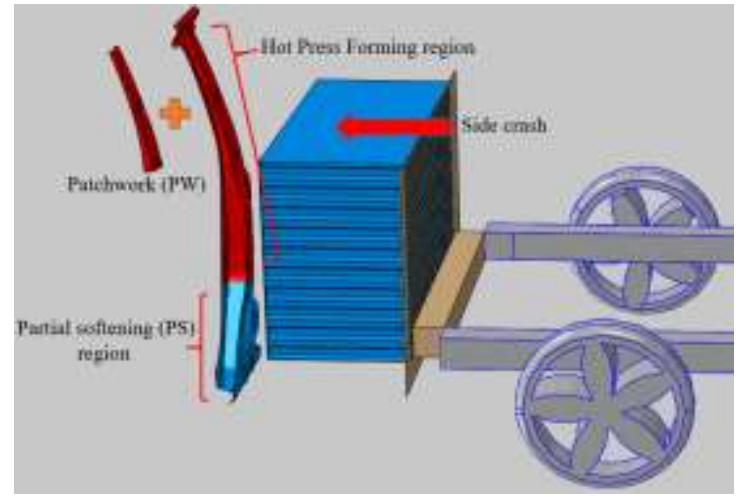

(a)

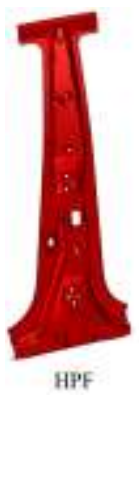

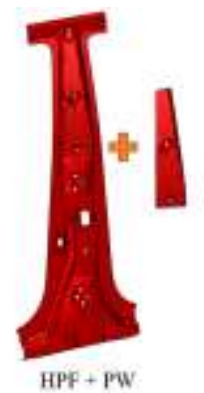
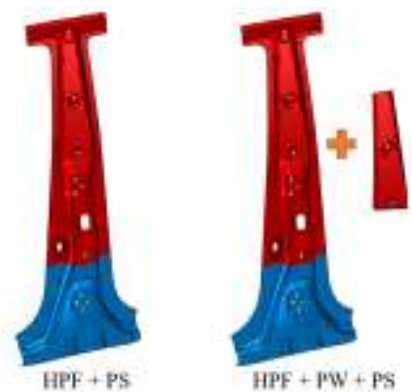

(b)

Fig. 1 (a) Function of center pillar during a side crash (b) four kinds of the center pillar

Table 1 Material properties of 22MnB5 (HPF) and 22MnB5 (PS)

\begin{tabular}{|c|c|c|c|c|}
\hline Material & $\begin{array}{c}\text { Tensile strength } \\
(\mathrm{MPa})\end{array}$ & $\begin{array}{c}\text { Elongation } \\
(\%)\end{array}$ & $\begin{array}{c}\text { Elastic modulus } \\
(\mathrm{GPa})\end{array}$ & $\begin{array}{c}\text { Vickers hardness } \\
(\mathrm{HV})\end{array}$ \\
\hline 22MnB5 (HPF) & 1500 & 5 & 210 & 440 \\
\hline 22MnB5 (PS) & 715 & $11 \sim 13$ & 210 & 225 \\
\hline
\end{tabular}

\subsection{Drop weight test and simulation.}

FE simulation for drop weight test was performed using ABAQUS/explicit software. Figure 2 shows the geometry modeling and welding constraints between HPF center pillar and PW. The fine mesh was defined at impact region and rough mesh was defined at other region to reduce computation time. The element type of center pillar and weld nodes were S4 and CNN3D2 respectively. The PW was welded to HPF center pillar with $1200 \times 440 \times 51.5$ mm dimension. As shown in Fig. 2 (b), the master weld node was defined on the element of center pillar and the slave weld node was defined on the element of PW. The mater and slave weld nodes were bonded and attachment method for the welding connector was point to point. The damage 
criterion and damage evolution of weld constraints were not applied, because the fracture at weld point didn't occurred. The detail conditions of weld condition for FE simulation was listed in Table 2.

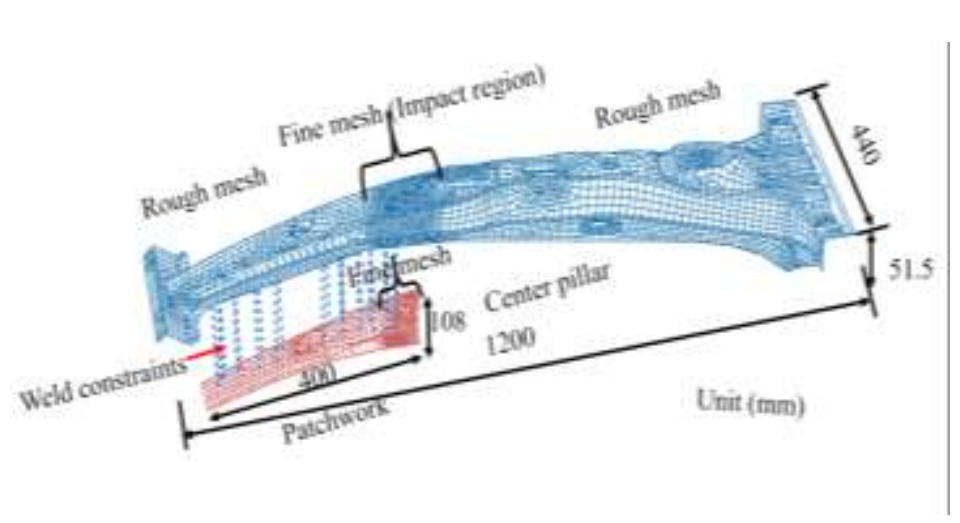

(a)

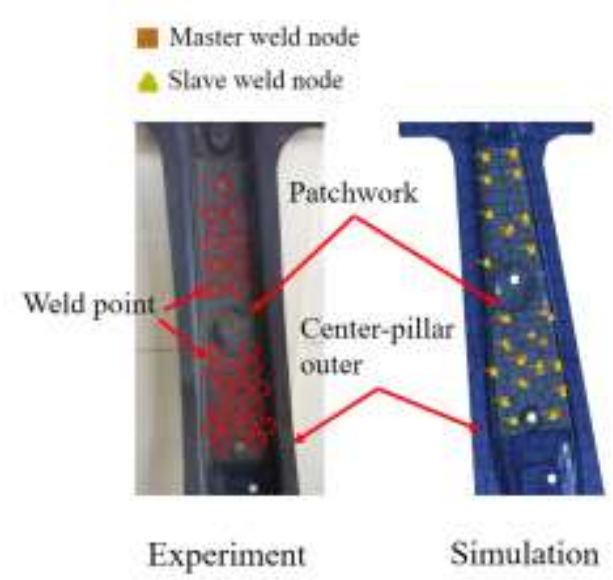

(b)

Fig. 2 Center pillar and PW: (a) geometry and mesh, (b) weld constraints.

Table 2 Spot weld conditions for FE simulation

\begin{tabular}{|c|c|c|c|}
\hline Attachment method & Additional mass $(\mathrm{kg})$ & Spot radius $(\mathrm{mm})$ & Degrees of freedom \\
\hline point - to - point & 0 & 3 & 0 \\
\hline
\end{tabular}

Figure 3 shows the simulation and experimental apparatus for the drop weight test. The center pillar was fixed by clamp as shown in Fig. 3 (a). The drop height was from center pillar to $610 \mathrm{~mm}$ and load cell was attached to impactor with a weight of $160 \mathrm{~kg}$. The drop weight simulation was also performed to compare with experiment data. The impactor velocity was $3.450 \mathrm{~m} / \mathrm{s}$ before collision. The 6 degrees of freedom of the center pillar were fixed at the zig region by clamp. The friction coefficient between the center pillar and impactor was 0.1 . The collision time was $0.18 \mathrm{~s}$. The detailed boundary conditions for the drop weight test are listed in Table 3. 


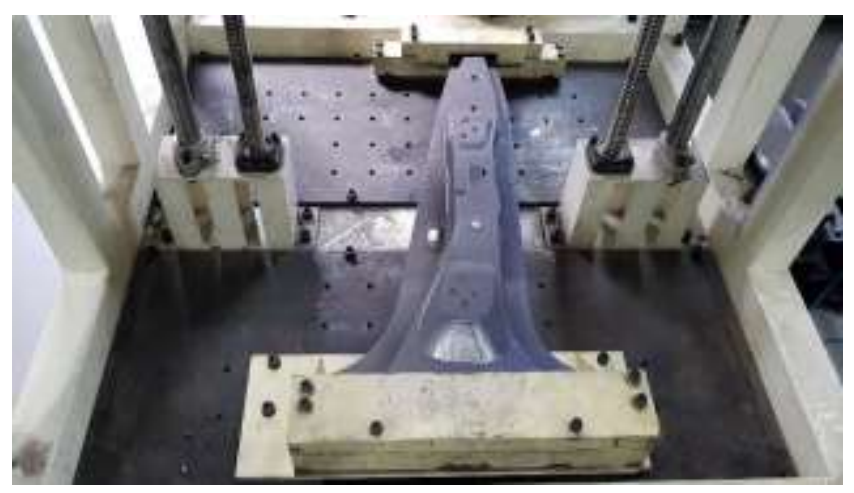

(a)

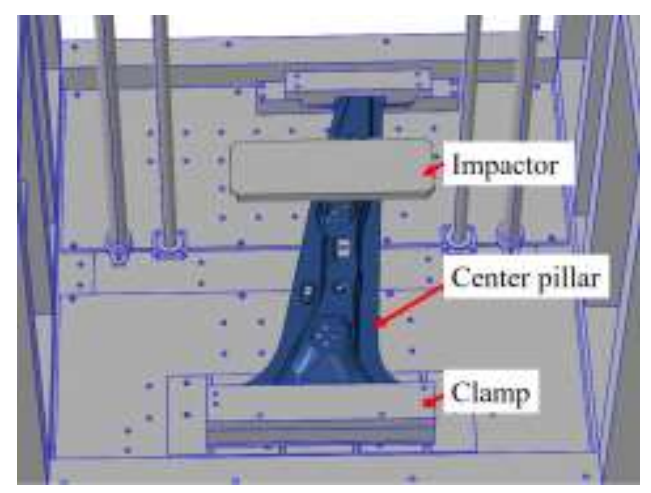

(b)

Fig. 3 Boundary conditions for drop weight test: (a) experiment, (b) simulation.

Table 3 Boundary conditions of simulation for the drop weight test

\begin{tabular}{|c|c|c|c|c|c|}
\hline $\begin{array}{l}\text { Impactor } \\
\text { Mass (kg) }\end{array}$ & $\begin{array}{l}\text { Collision } \\
\text { Time (s) }\end{array}$ & $\begin{array}{l}\text { Impactor } \\
\text { velocity } \\
(\mathrm{m} / \mathrm{s})\end{array}$ & $\begin{array}{l}\text { Drop } \\
\text { height } \\
(\mathrm{mm})\end{array}$ & $\begin{array}{c}\text { Initial } \\
\text { potential } \\
\text { Energy }(\mathrm{J})\end{array}$ & $\begin{array}{c}\text { Friction } \\
\text { coefficient } \\
\text { between front } \\
\text { bumper beam } \\
\text { and impactor }\end{array}$ \\
\hline 160 & 0.18 & 3.45 & 610 & 956 & 0.1 \\
\hline
\end{tabular}

\subsection{Side crash simulation}

The Moving Deformation Barrier (MDB) was modeled for side crash simulation as following with IIHS. Figure 4 shows the geometry modeling of MDB with $450 \times 1000 \times 650 \mathrm{~mm}$. The MDB consists of two parts: a main honeycomb block and aluminum sheet used as cover layer. Both two parts were adhesively bonded to each other. The main honeycomb block which was hexagonal shape with cell size of $22 \mathrm{~mm}$ was made Al5052 foil. The foil thickness was $0.05 \mathrm{~mm}$ and crush strength of $31 \mathrm{MPa}$. The detailed material properties of MDB was listed in Table. The weight of MDB was $1,360 \mathrm{~kg} \pm 5 \mathrm{~kg}$ with deformable element 
and the center of mass was $1000 \mathrm{~mm}$ from front deformable element as shown in Fig. 4 The MDB roll (Ix), pitch (Iy) and yaw (Iz) moments of inertia were $542 \mathrm{~kg} \cdot \mathrm{m}^{2}, 2471 \mathrm{~kg} \cdot \mathrm{m}^{2}$, and 2,757 $\mathrm{kg} \cdot \mathrm{m}^{2}$, respectively [24].

Figure 5 shows the geometry modeling and material section of the automobile and pillars. The simulated parts had the same dimensions of automobile was $4580 \times 1820 \times 1250 \mathrm{~mm}$. As the actual automobile, specifically, the shell model was used and the element type was set to S4 to reduce the hourglass effect and measure absorbed energy in detail. Because the shape of the automobile was complex, curved, and had many holes, the automobile part was meshed using a bottom up mesh technique. The collision region was finely meshed, while regions away from the collision area were roughly meshed. The thickness of center pillars outer and reinforcement, doors and other frames were $1.2 \mathrm{~mm}, 1.2 \mathrm{~mm}$ and $2.0 \mathrm{~mm}$, respectively. The multi materials were used to design sedan. The material section of center pillar, patchwork, frame and other parts were HPF with PS, HPF, DP590 and CR420 (mild steel), respectively.

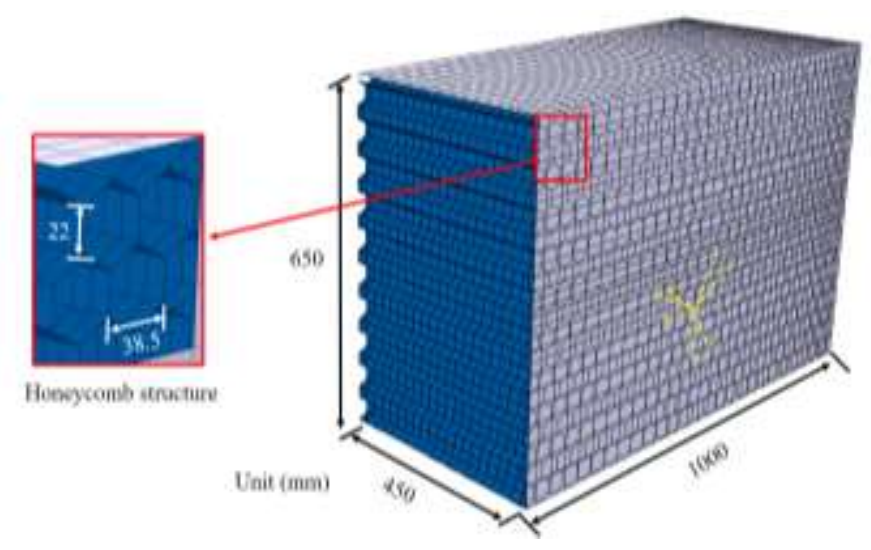

Fig. 4 Geometry modeling of MDB for side crash simulation.

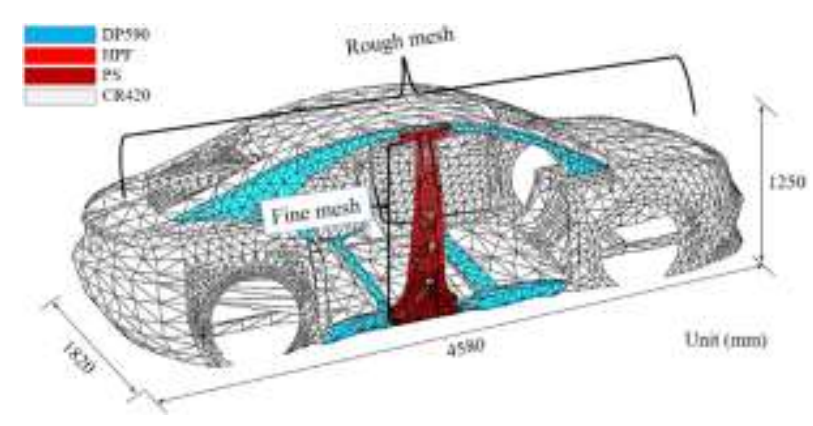


Fig. 5 Geometry and material sections of the sedan for side crash test.

Figure 6 shows a schematic diagram of the side crash test. Side crash tests is a stationary vehicle test that evaluates the impact characteristics when an impactor equipped with an MDB collides with the side region of a stopped vehicle according to IIHS regulation. The impactor with MDB has a collision velocity of $50 \mathrm{~km} / \mathrm{h}(13.8 \mathrm{~m} / \mathrm{s})$ and hits the stopped vehicle at a 90 degree angle as shown in Fig. 6 . The mass of the sedan and impactor with MDB were 1420 and $1360 \mathrm{~kg}$, respectively. The 6 degrees of freedom of the stopped vehicle were fixed on the ground. The friction coefficient between the ground and impactor's wheel was 0.1 . The collision time was $0.1 \mathrm{~s}$. Since the opposite side of the collision zone would not be deformed, the half body of the stopped vehicle (Sedan) was selected as a rigid body in order to reduce the analysis time. The detailed side crash conditions are given in Table 4. Mass scaling was not used, and the stable time increment size was $1.67821 \mathrm{E}-8 \mathrm{~s}$.

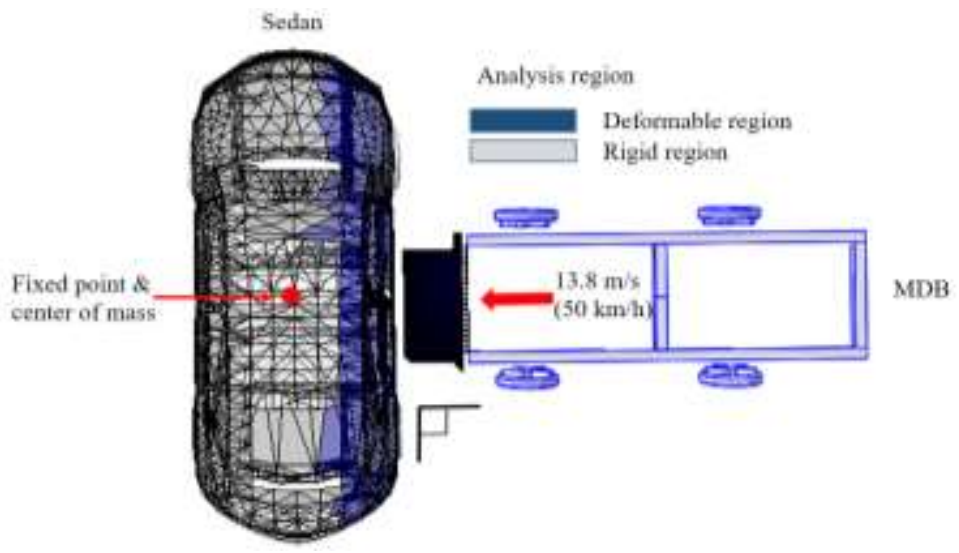

Fig. 6 Boundary conditions for side crash simulation.

Table 4 Collision conditions of simulation for side crash 


\begin{tabular}{|c|c|c|c|c|c|}
\hline $\begin{array}{c}\text { Sedan } \\
\text { Mass }(\mathrm{kg})\end{array}$ & $\begin{array}{c}\text { MDB } \\
\text { mass }(\mathrm{kg})\end{array}$ & $\begin{array}{c}\text { Collision } \\
\text { time } \\
(\mathrm{sec})\end{array}$ & $\begin{array}{c}\text { Impactor } \\
\text { velocity } \\
(\mathrm{m} / \mathrm{s})\end{array}$ & $\begin{array}{c}\text { Friction } \\
\text { Energy }(\mathrm{kJ})\end{array}$ & $\begin{array}{c}\text { coefficient } \\
\text { between ground } \\
\text { and vehicle }\end{array}$ \\
\hline 1420 & 1500 & 0.1 & 13.8 & 142 & 0.1 \\
\hline
\end{tabular}

\subsection{Energy absorption method}

In the side crash simulation, the various energies such as elastic, plastic, kinetic, friction and viscoelastic energy were transformed by deformation during collision. Among these energies, the absorbed energy by deformation was experimentally calculated using load- displacement data as follow Eq. (4) [25]:

$$
E_{a b}=\int_{0}^{s} F(x) d x
$$

where $\boldsymbol{E}_{\boldsymbol{a} \boldsymbol{b}}, \mathrm{s}$ and F are absorbed energy, the crash displacement and impulsive force, respectively.

The specific energy absorption (SEA) was obtained by Eq. (5):

$$
\mathrm{SEA}=\frac{E_{a}}{M}
$$

where $M, \boldsymbol{E}_{\boldsymbol{a}}$ are total mass and absorbed energy.

When the SEA is a high value, this means energy absorption capability is high. However, this is not an exactly but approximate estimation method. This method cannot determine elastic and plastic deformation energy.

In this study, to calculate the accurate absorbed energy such as elastic and plastic dissipated energies and analysis the distribution of energy flow in the time domain, the integrating the stress-strain curve data per unit element volume were used.

Figure 7 shows the meshed shell with S4 element type to calculate the energy variable data accurately and avoid the hourglass effect. As shown in Fig. 7 (a), the shell element has 4 point, which are inside midsurface, in contrast with solid element type. Because the mid-surface was used for analysis, the change of 
shell thickness was not visually expressed and the strain of thickness direction of shell element was calculated as Eq. (6):

$$
\varepsilon_{33}=\frac{v}{1-v}\left(\varepsilon_{11}+\varepsilon_{22}\right)
$$

Treating these as logarithmic strains,

$$
\ln \frac{t}{t_{o}}=-\frac{v}{1-v} \ln \left(\frac{l_{0}}{l}\right)=-\frac{v}{1-v} \ln \left(\frac{A}{A^{o}}\right)
$$

where $l, \mathrm{t}, \mathrm{v}$, and A are the element length, thickness, Poisson's ratio, and area on the shell's reference surface, respectively.

The change of shell thickness was leads to the following Eq. (8)

$$
\frac{t}{t_{o}}=\left(\frac{A}{A_{o}}\right)^{\left(-\frac{v}{1-v}\right)}
$$

From above equations, the element volume of each mesh can be measured by Eq. (9) after deformation.

$$
V_{\text {element }}=A t_{o}\left(\frac{A}{A_{o}}\right)^{\left(-\frac{v}{1-v}\right)}
$$

The stress-strain curve describing the calculation of absorbed energy per element volume during deformation is shown in Fig. 7 (b) and (c).

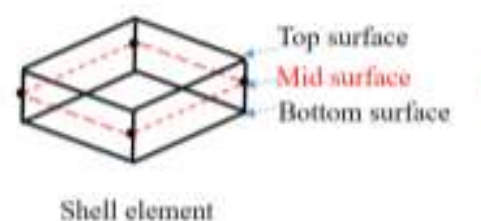

Shell element

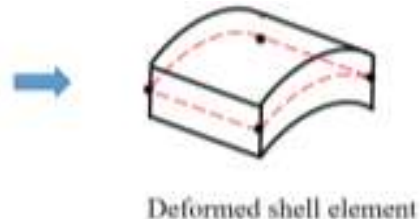

Deformed shell element 


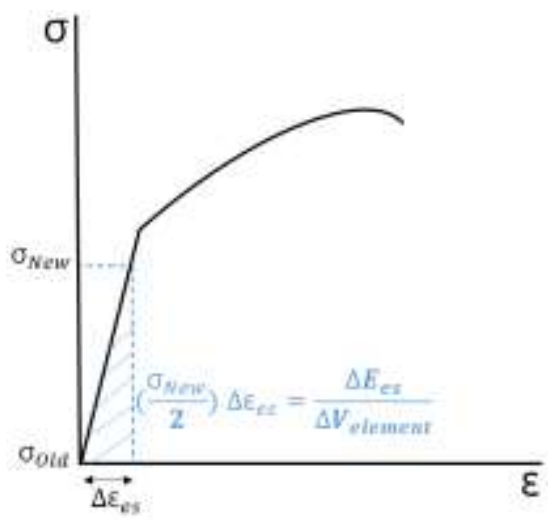

(b)

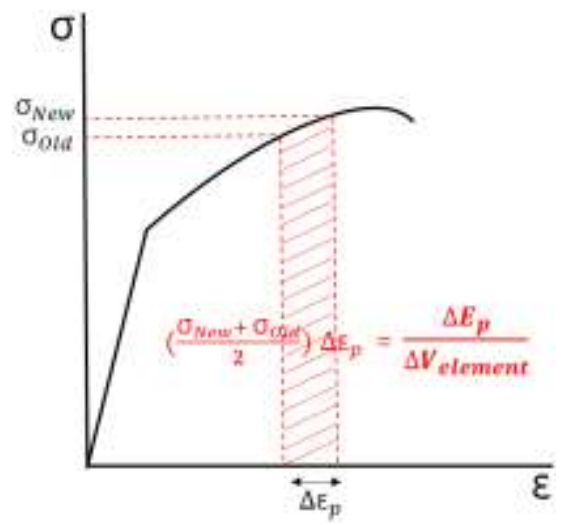

(c)

Fig. 7 Shell element and energy absorption of stress-strain curve per element volume: (a) element deformation, (b) elastic strain energy and (c) plastic deformation energy.

As shown in Fig. 7 (b) and (c), the specific elastic and plastic deformation energies are measured by Eq. (10) and (11):

$$
\begin{aligned}
\Delta E_{e s} & =\frac{1}{2}\left(\sigma_{\text {New }}\right) \Delta \varepsilon_{e s} \Delta V \\
\Delta E_{p} & =\frac{1}{2}\left(\sigma_{\text {old }}+\sigma_{\text {New }}\right) \Delta \varepsilon_{p} \Delta V
\end{aligned}
$$

where $\Delta \sigma_{i}, \sigma_{\text {New }}, \sigma_{\text {old }}, \sigma^{u}$, and $\Delta \boldsymbol{V}$ are the stress increment, new stress, previous stress, userdefined equation stress, and specific element volume, respectively.

The internal energy can be expressed by integrating Eq. (12):

$$
E_{I}=\int_{o}^{t}\left(\int_{V} \sigma^{u}: \dot{\varepsilon} d V\right) d t
$$

Then, $\dot{\varepsilon}=\dot{\varepsilon}^{e s}+\dot{\varepsilon}^{p}+\dot{\varepsilon}^{c}$, and $E_{I}$ can be separated as in Eq. (13):

$$
E_{I}=\int_{o}^{t}\left(\int_{V} \sigma^{u}: \dot{\varepsilon} d V\right) d t=\int_{o}^{t}\left(\int_{V} \sigma^{u}: \dot{\varepsilon}^{e s} d V\right) d t+\int_{o}^{t}\left(\int_{V} \sigma^{u}: \dot{\varepsilon}^{p} d V\right) d t+\int_{o}^{t}\left(\int_{V} \sigma^{u}: \dot{\varepsilon}^{c} d V\right) d=E_{e s}+E_{p}+E_{c}
$$


where $\dot{\varepsilon}^{e s}, \dot{\varepsilon}^{p}$, and $\dot{\varepsilon}^{c}$ are the elastic, plastic, and creep strain rates, respectively; $E_{e s}, E_{p}$, and $E_{c}$ are the elastic, plastic, and creep strain energies, respectively.

The elastic strain energy $\left(E_{e s}\right)$ results from linear deformation, whereas the energy dissipated by plasticity $\left(E_{p}\right)$ occurs when the permanent deformation of the meshed element begins. The elastic and plastic strain regions are linear and non-linear, respectively. The aforementioned energies are defined by Eq. (14) and (15):

$$
\begin{gathered}
E_{e s}=\int_{o}^{t}\left(\int_{V} \sigma^{u}: \dot{\varepsilon}^{e s} d V\right) d t=\sum_{t} \sum_{i=1}^{n} \frac{1}{2} \sigma_{i} \varepsilon_{i} \Delta V_{i} \\
E_{p}=\int_{o}^{t}\left(\int_{V} \sigma^{u}: \dot{\varepsilon}^{p} d V\right) d t
\end{gathered}
$$

where $\mathrm{V}$ and $\mathrm{E}$ are the volume and elastic modulus, respectively.

In this study, element set of PW, PS and MDB were selected as shown in Fig. 8. The $E_{e s}$ and $E_{p}$ of the four kinds of the center pillar were compared during side crash. This was because the elastic strain and plastic deformation energies account for most of the internal energy, which is known as the absorbed energy during collision. $E_{e s}$ and $E_{p}$ of PS and PW were calculated with the above equation during the deformation of the element according to four types of the center pillar as shown in Fig. 1 (b).
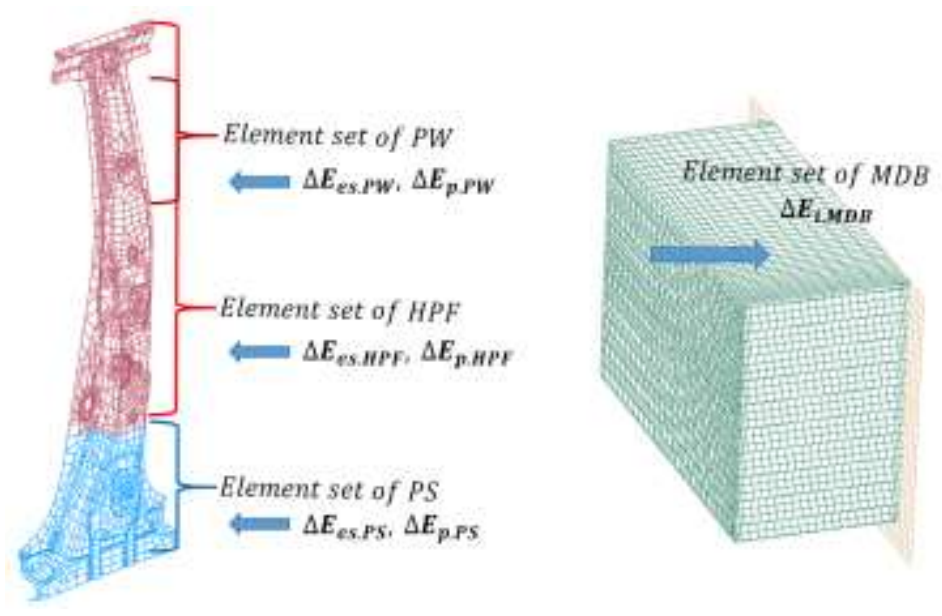

Fig. 8 Energy distribution of center pillar and MDB. 
In this study, the FLD for 22MnB5 (HPF, PS) that was obtained earlier was applied to obtain accurate data for the fracture mechanism ${ }^{26}$. Because the sheet metal in the simulation is very thin, local necking could not be realized in the shell element. Forming limit curve data obtained through testing was applied to the simulation. The simulation then proceeded to predict the onset of necking instability in the sheet metal using the FLD curves of 22MnB5 (HPF) and 22MnB5 (PS) [26] in Abaqus/explicit.

\section{Results and discussions}

\subsection{Comparison of impulse between experiment and simulation}

Figure 9 compares the experimental and simulation results after the collision test for the HPF center pillar with PW and PS. Figure 9 (a) and Figure 9 (b) show the top and side views of the center pillar, respectively, between the experiment and the simulation. The figure shows that the deformation behaviors of the experiment and the simulation were similar.

Figure 10 shows the comparison result of impactor load between experiment and simulation according to time. The maximum impact load of the experiment and simulation were $9.5 \mathrm{kN}$ and $12.7 \mathrm{kN}$, respectively. The value of impulse and collision time between the experiment and simulation were $799 \mathrm{~N} \cdot \mathrm{s}, 0.165 \mathrm{~s}$ and $787 \mathrm{~N} \cdot \mathrm{s}, 0.117 \mathrm{~s}$, respectively. From above results, the validation of simulation and experiment was confirmed and these material sections of mechanical properties were used for side crash simulation.

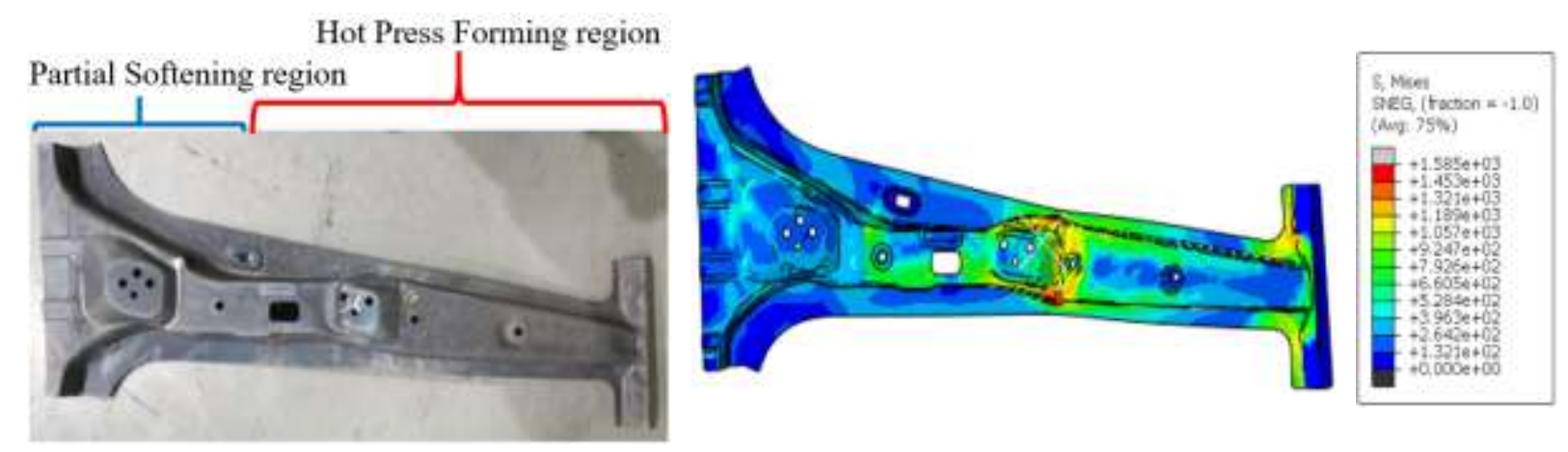




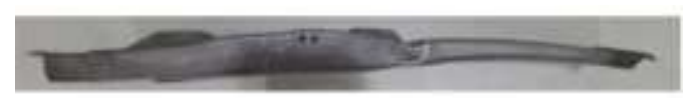

(a)

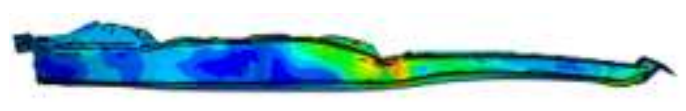

(b)

Fig. 9 Comparison of the HPF center pillar with PW and PS after the drop weight test: (a) top and side view after the experiment (b) top and side view after the simulation.

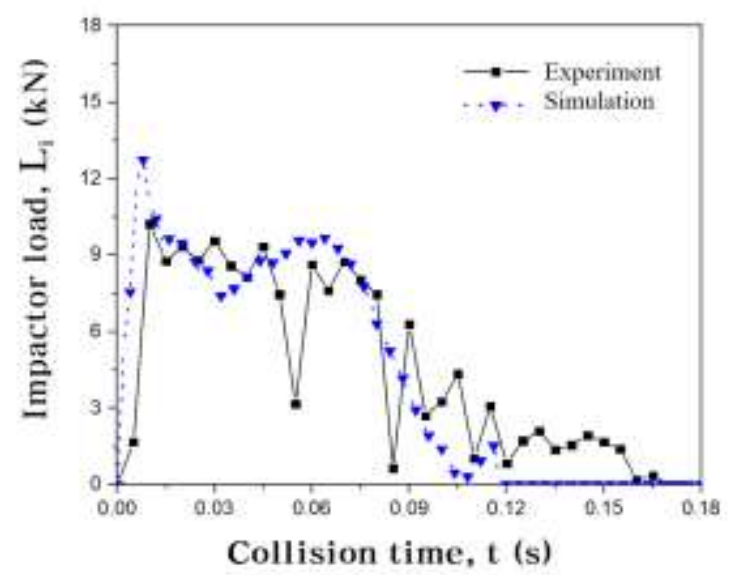

Fig. 10 Comparison of the impactor load of the HPF center pillar with PW between the experiment and the simulation.

\subsection{Side crash simulation}

The first law of thermodynamics is the law of conservation of energy. In an isolated system, it indicates that the total energy remains constant even when the energy changes from one form to another. It can be converted into various types such as kinetic energy, potential energy, internal energy and friction dissipation energy in a automobile side impact. In general, most of the kinetic energy in a automobile crash causes a large change in internal energy due to elastic and plastic deformation. Total energy can be measured as the sum of several energies using the following Eq. (1): 


$$
E_{\text {total }}=E_{i}+E_{k}+E_{v}+E_{f}+E_{e}
$$

where $\boldsymbol{E}_{\boldsymbol{i}}, \boldsymbol{E}_{\boldsymbol{k}}, \boldsymbol{E}_{\boldsymbol{v}}, \boldsymbol{E}_{\boldsymbol{f}}$ and $\boldsymbol{E}_{\boldsymbol{e}}$ are internal energy, kinetic energy, viscous dissipation energy, friction dissipation energy and external work.

Figure 11 shows the distribution of $E_{\text {total }}$ during side crash time. The total energy is $142 \mathrm{~kJ}$. First, the velocity of MDB decreased gradually by friction between ground and MDB before collision. The $E_{k}$ decreased sharply during the collision because the velocity of the MDB decreases, while the $E_{i}$ increased by plastic, elastic deformation and $E_{v}$ increased to $5.8 \mathrm{~kJ}$ by material damping. During collision time, other energies increased but total energies were maintained. For example, when the collision time was 0.0385 sec, the $E_{i . M D B}, E_{i . S e d a n}, E_{k}, E_{v}$ and $E_{f}$ were $45.1 \mathrm{~kJ}, 45.7 \mathrm{~kJ}, 45.4 \mathrm{~kJ}, 2.9 \mathrm{~kJ}$ and $5.9 \mathrm{~kJ}$, respectively as shown in Fig. 11 (a) and (b). The value of $E_{e}$ is $0 \mathrm{~kJ}$ because the external work has not been done.

Figure 11 (c) shows the percentage of energy at $t=0.071 \mathrm{sec}$ when MDB velocity is about $0 \mathrm{~m} / \mathrm{s}$. The $E_{i . M D B}$ was $82.5 \mathrm{~kJ}$ and this energy occupied $58.1 \%$ of the total energy. This means that the $58.1 \%$ of total energy (142 kJ) was absorbed to MDB during side crash. On the other hand, the sum of $E_{i . S e d a n}$ by doors, automobile body and other frames were $44.6 \mathrm{~kJ}$ and among these energies, the $5.4 \mathrm{~kJ}$ energy was absorbed to center pillar and PW. Following above data, the center pillar and PW took $12 \%$ of the sedan internal energy. In this study, the center pillar inner part was not included. If the center pillar inner part had been included, the center pillar such as center pillar outer, inner and PW could be expected to take 15 18\% of the internal energy. The effect of PW and PS on energy distribution and intrusion resistance was investigated following as below. 


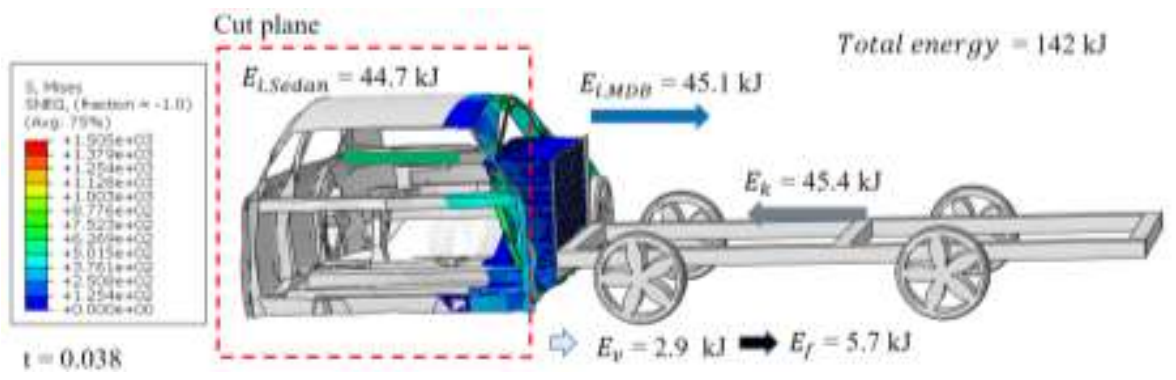

(a)

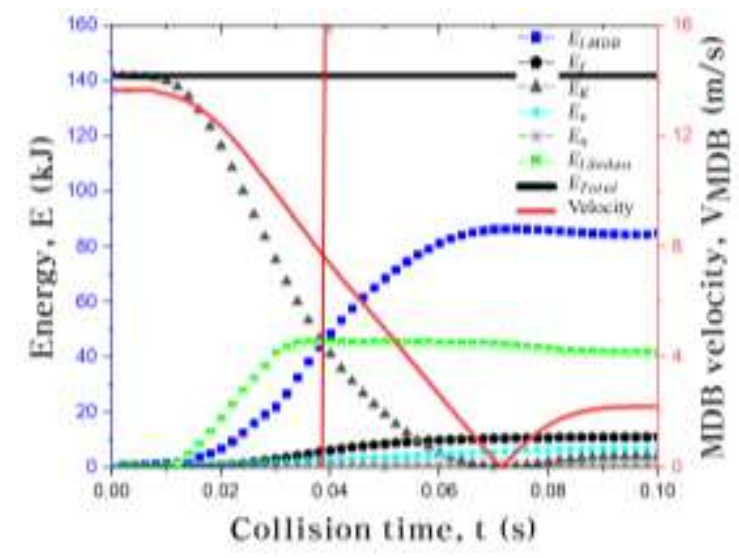

(b)

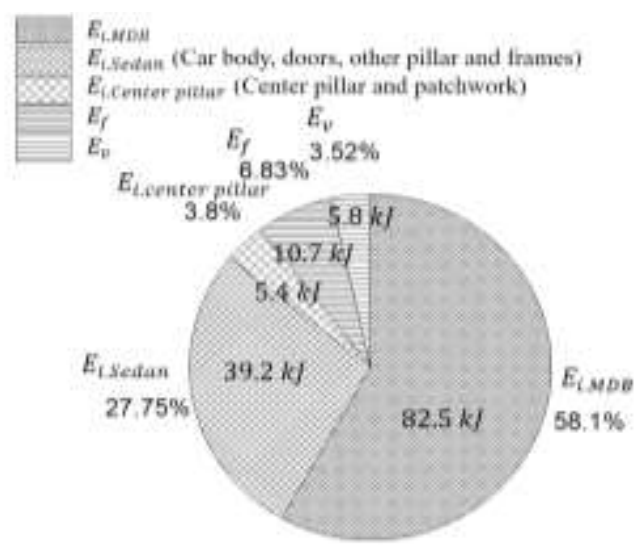

(c)

Fig. 11 Energy conversion during side crash: (a) flow of energy distribution at $t=0.0385 \mathrm{~s}$, (b) distribution of energies according to collision time, (c) distribution of energy conversion at $\mathrm{t}=0.071 \mathrm{~s}$.

Figure 12 shows the elastic strain energy $\left(E_{e s}\right)$ of the four kinds of the center pillar (HPF, HPF with PW, HPF with PS, HPF with PW and PS) during side crash. For the HPF center pillar, the maximum $E_{\text {es }}$ was $0.851 \mathrm{~kJ}$ at collision time $(\mathrm{t})=0.064 \mathrm{~s}$ and then $E_{\text {es }}$ decreased to $0.30 \mathrm{~kJ}$ after collision because of elastic recovery. When the PW was applied to the $\mathrm{HPF}$ center pillar, the maximum $E_{e s}$ increased to $0.928 \mathrm{~kJ}$ at $\mathrm{t}$ $=0.056 \mathrm{~s}$. Because the rigidity of the HPF center pillar with PW increased, the absorption of elastic energy improved significantly. However, for the HPF center pillar with PS, the maximum $E_{\text {es }}$ decreased to 0.655 $\mathrm{kJ}$ at $\mathrm{t}=0.061 \mathrm{~s}$ than HPF. When the PS was applied to the bottom region of the HPF center pillar, because the stiffness of HPF center pillar with PS decreased, the absorbed energy decreased in terms of elastic deformation. 
Figure 13 shows the maximum $E_{e s}$ according to four types of the center pillar to evaluate energy absorption of PW and PS in detail. The $E_{\text {es }}$ of HPF center pillar with PW was $0.1 \mathrm{~kJ}$ and this was occupied by $10 \%$ of total HPF center pillar with PW. While, the $E_{e s}$ of HPF center pillar with PS decreased to 0.655 0.660 regardless of having PW.

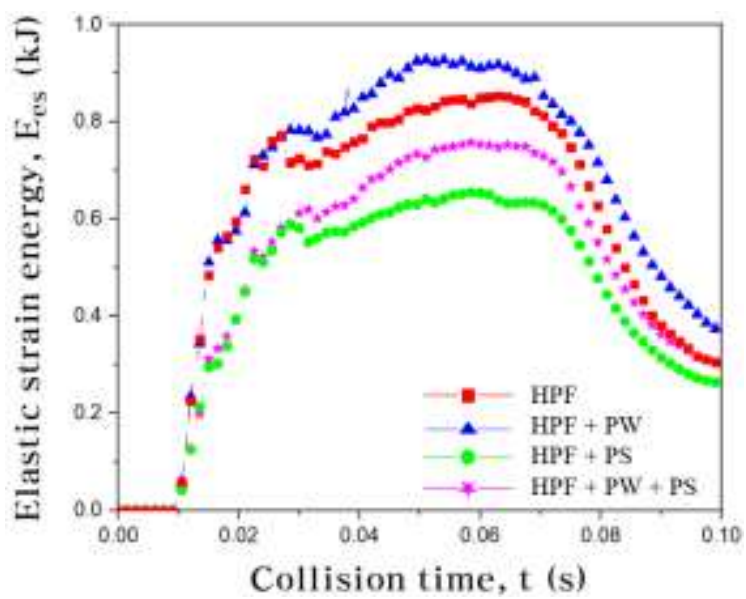

Fig. 12 Elastic strain energy $\left(E_{e s}\right)$ of the four kinds of the center pillar during side crash.

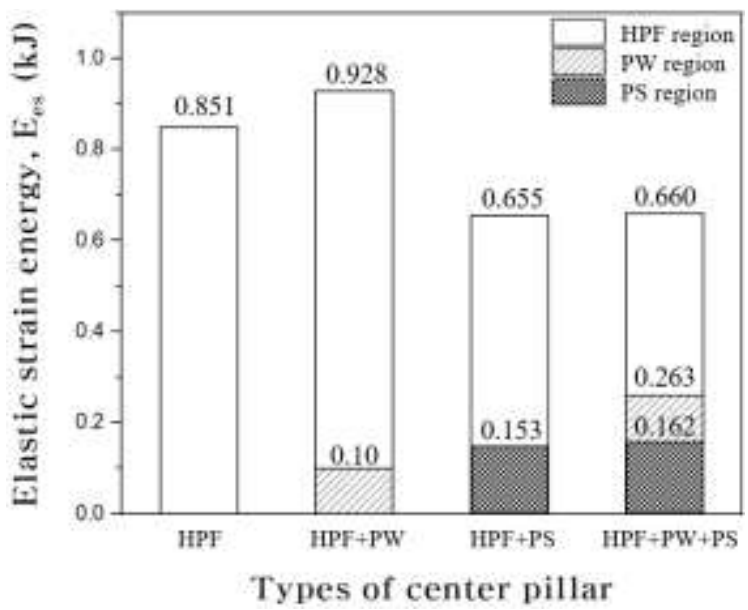

Fig. 13 Maximum elastic strain energy $\left(E_{e s}\right)$ according to four types of the center pillar. 
Figure 14 shows the plastic deformation energy $\left(E_{p}\right)$ of the four kinds of the center pillar during side crash. For the HPF center pillar, the $E_{p}$ increased to $4.538 \mathrm{~kJ}$ during deformation. The $E_{p}$ was maintained after collision and this energy differed from the $E_{\text {es }}$ because permanent deformation occurred. For the HPF center pillar with PS, the $E_{p}$ increased to $4.998 \mathrm{~kJ}$ at $0.1 \mathrm{~s}$. The $E_{p}$ of the HPF center pillar with PS was higher than that of the HPF center pillar. When the PS was applied to HPF center pillar, a large deformation occurred at soft bottom region of center pillar because of the ductility. As a result, the absorbed energy improved $9.3 \%$. However, there was no difference in absorbed energy between the HPF center pillar and HPF center pillar with PW in terms of plastic deformation.

Figure 15 shows the maximum $E_{p}$ according to four types of center pillar. For the HPF center pillar with PS and HPF center pillar with PW and PS, the 2.52 2.54 kJ of $E_{p}$ was absorbed at the PS region, which was the bottom region of the center pillar. In terms of plastic deformation, the effect of PW was little unlike the elastic strain energy, while, the $E_{p}$ of the PS region was occupied by $49.8 \sim 50.9 \%$ among total plastic deformation energy between the HPF center pillar with PS and HPF center pillar with PW and PS.

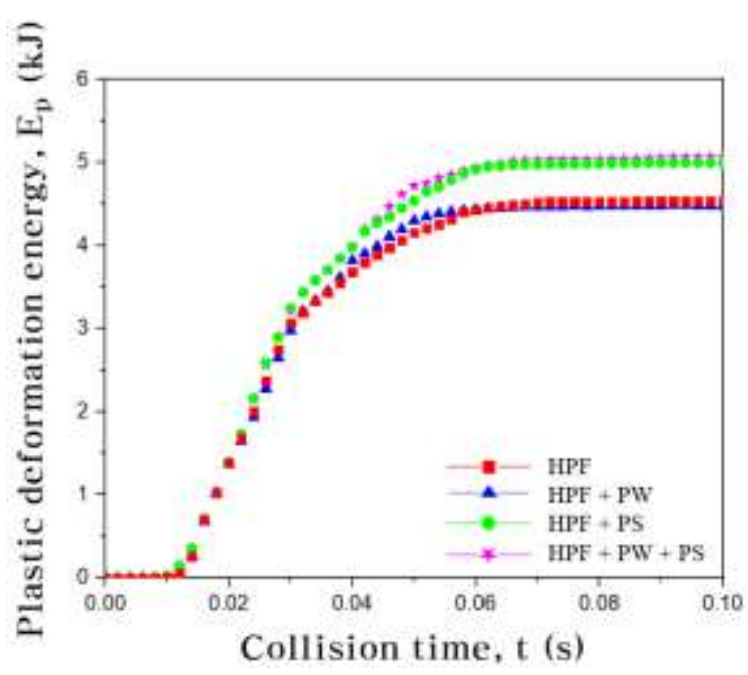

Fig. 14 Plastic deformation energy $\left(E_{p}\right)$ of the four kinds of the center pillar during side crash. 


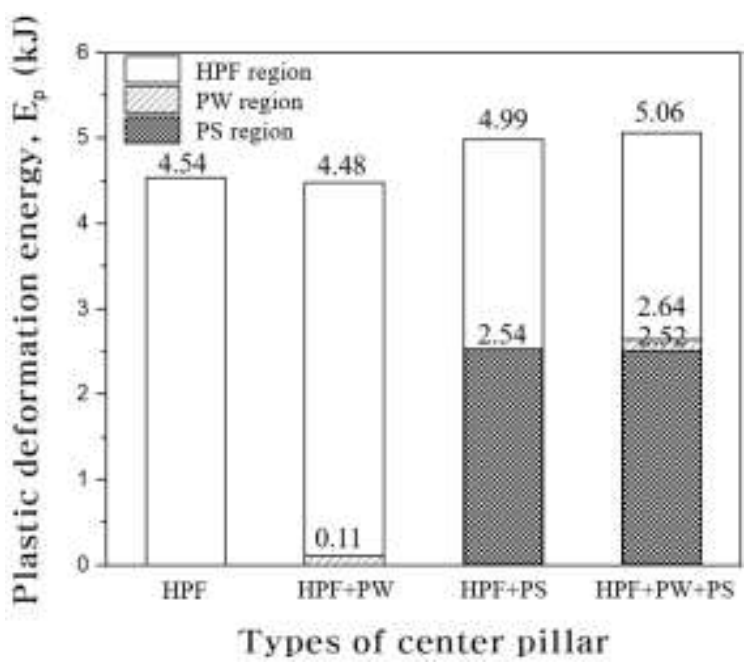

Fig. 15 Maximum plastic deformation energy $\left(E_{p}\right)$ according to four types of the center pillar.

Figure 16 shows the internal energy $\left(E_{i}\right)$ of the four kinds of the center pillar during side crash. The total internal energy resulting from a collision consists of several energies and can be expressed by the following Eq. (2):

$$
E_{i}=E_{e s}+E_{p}+E_{a}+E_{o t h e r s}
$$

where $\boldsymbol{E}_{\boldsymbol{i}}$ is the internal energy, $\boldsymbol{E}_{\boldsymbol{e}}$ is the elastic strain energy, $\boldsymbol{E}_{\boldsymbol{p}}$ is the plastic deformation energy, $\boldsymbol{E}_{\boldsymbol{a}}$ is the artificial strain energy, and $\boldsymbol{E}_{\boldsymbol{o t h e r}}$ is the energy dissipated by creep, viscoelasticity and swelling.

Generally, $E_{e s}$ and $E_{p}$ are the dominant factors of $E_{i}$ during collision and other energies are relatively small. Therefore, in this study, the internal energy was expressed as the sum of $E_{\text {es }}$ and $E_{p}$ excluding other types of energy such as viscoelasticity, friction, and creep energy. In terms of internal energy, when the PS technique was applied to the HPF center pillar, there was a slight difference in the absorbed energy. However, the synergy effect occurred when the PW and PS were applied to the HPF center pillar, and a large amount of energy was absorbed as shown in Fig. 16. 
Figure 17 (a) shows the maximum internal energy according to four types of the center pillars. As shown in Fig. 17 (a), it can be confirmed that there is almost no difference in the plastic deformation energy between the HPF center pillar with and without PW. The PW was welded on the upper part of the HPF center pillar to increase the stiffness, but the impact region is applied from the middle to the bottom as shown in Fig. 17 (b). Therefore, small deformation occurred in the PW. Likewise, for comparison between the HPF center pillar with PS and the HPF center pillar with PW and PS, there were also similar phenomena in the absorbed plastic deformation energy. From the above results, it is necessary to review whether the PS technology is applied in light of the relationship between technical performance and manufacturing cost.

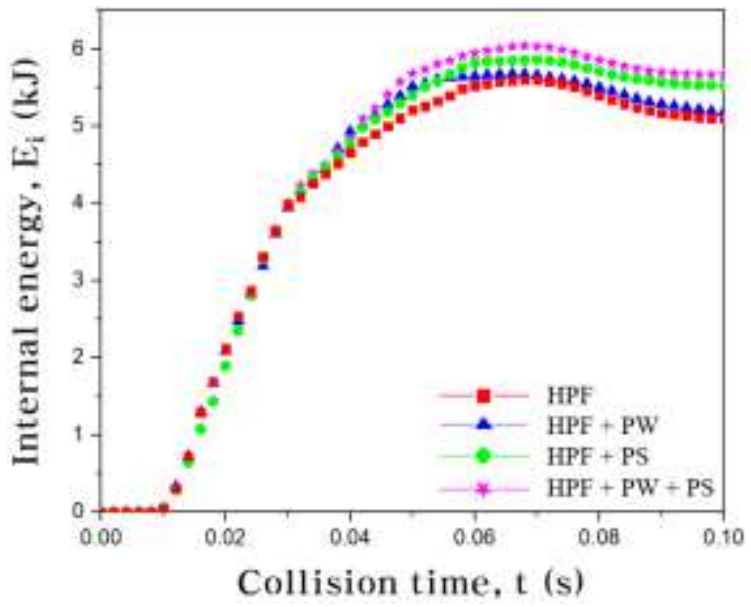

Fig. 16 Internal energy $\left(E_{i}\right)$ of the four kinds of the center pillar during side crash. 


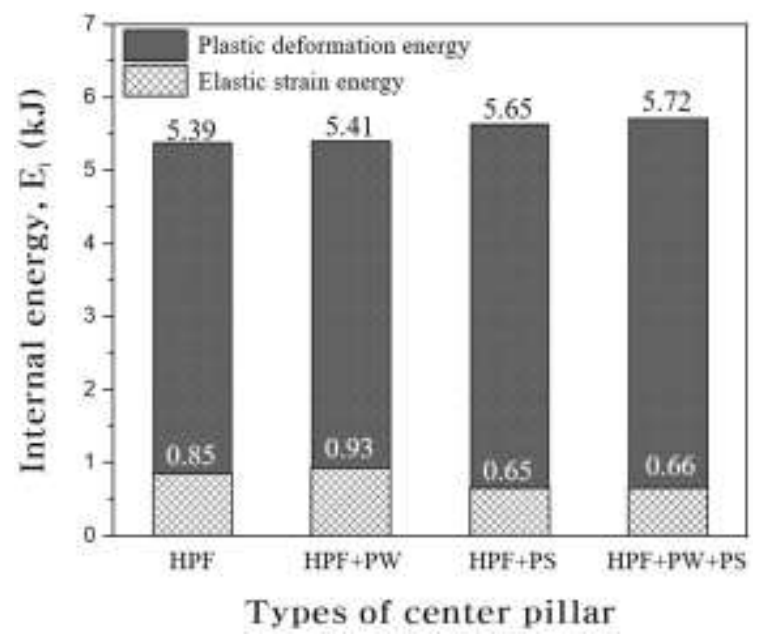

(a)

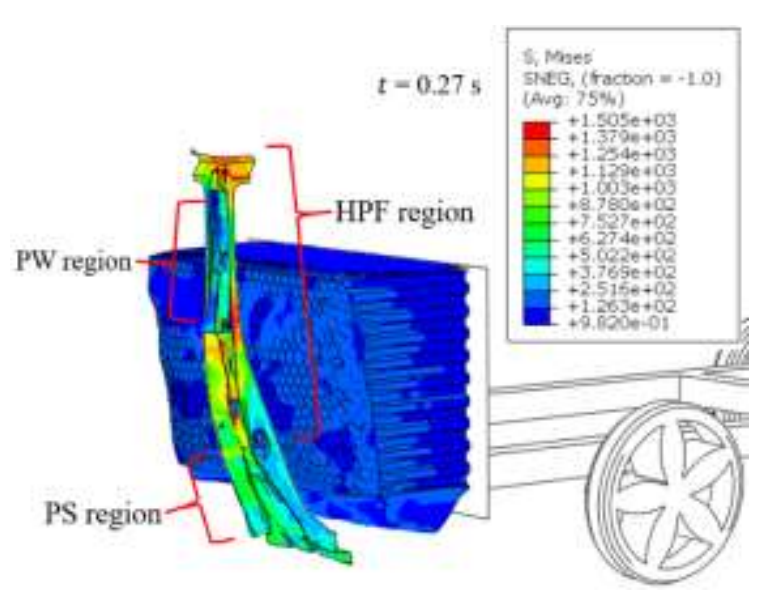

(b)

Fig. 17 (a) maximum internal energy $\left(E_{i}\right)$ according to four types of the center pillar and (b) stress distribution of center pillar during collision.

During a side crash, a large amount of absorbed energy is important. However, if the material is soft and a large deformation occurs, the intrusion displacement increases and the passenger will be in danger. Therefore, it is important to evaluate intrusion displacement for passenger safety as well as collision energy absorption.

As shown in Fig. 18 (a), because the both center pillar and MDB were deformed during collision, the maximum intrusion displacement was calculated by Eq. (3):

$$
d_{\operatorname{max.i}}=d_{\max . D M B}(t)-L_{b}
$$

where $\boldsymbol{d}_{\boldsymbol{m a x . D M B}}$ is the maximum displacement of DBM and $\boldsymbol{L}_{\boldsymbol{b}}$ is the barrier length.

The evaluation method for the anti-intrusion resistance was introduced in IIHS instruction. The center pillar has primarily performance related to anti-intrusion resistance against side impact. In the IIHS rating protocol [27], the center line of vehicle's seat was generally standard of the measured intrusion displacement as shown in Fig. 18 (b), with categories of good, acceptable, marginal and poor [28, 29]. In 
this study, multi structure such as automobile seat, dummy and windows were not considered so that the maximum intrusion of HPF center pillar with PW was used as the acceptable distance with acceptable level. As shown in Fig. 18 (b), the maximum intrusion displacement of the HPF center pillar and the HPF center pillar with PW were $-134.0 \mathrm{~mm}$ and $-123.9 \mathrm{~mm}$, respectively. When the stiffness of the upper part was strengthened with PW, the safety for the intrusion displacement was also improved by $7.5 \%$. Likewise, in case of the HPF center pillar with PS, the maximum intrusion displacement was $-123.1 \mathrm{~mm}$. this result was similar with HPF center pillar with PW. On the other hand, the maximum intrusion displacement of the HPF center pillar with PW and PS was $-116.1 \mathrm{~mm}$, which was improved than HPF center pillar by $13.4 \%$. When the PW and PS were combined, the synergy effect occurred.

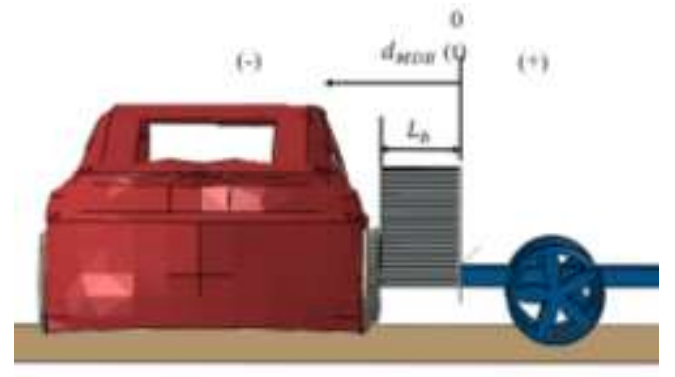

(a)

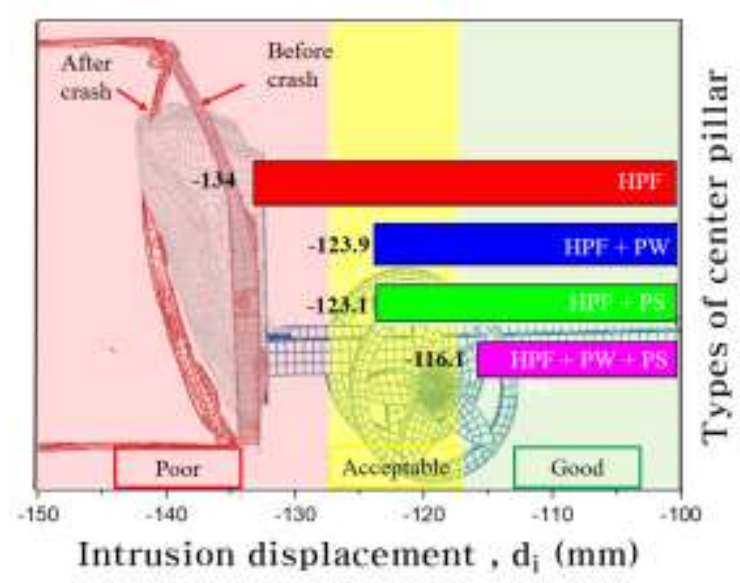

(b)

Fig. 18 (a) introduction, (b) simulation data for intrusion displacement $\left(d_{i}\right)$ of the four kinds of the center pillar.

\section{Conclusions}


In this study, when the side crash simulation performed, the effect of HPF center pillar with PW and PS on energy distribution and anti-intrusion resistance were investigated and the following conclusions were obtained:

1. During side crash collision, the effect of PW for HPF center pillar on plastic deformation energy was little but important on elastic strain energy and intrusion resistance. When the PW was applied to HPF center pillar to strengthen the stiffness, the elastic strain energy and intrusion displacement were 10.0, $7.5 \%$ respectively.

2. Because the PS technique provided ductility to the lower region of the HPF center pillar, the large deformation occurred and the plastic deformation energy was improved by $10 \%$ significantly. The $E_{p}$ of the PS region was occupied by $49.8 \sim 50.9 \%$ among plastic deformation energy of HPF center pillar with PS.

3. In terms of total internal energy, the PS technique was better than PW technique. In addition, the maximum intrusion displacement of the HPF center pillar with PS was similar with the HPF center pillar with PW. In case of the HPF center pillar with PW and PS, the maximum intrusion displacement was improved than HPF center pillar by $13.4 \%$. The synergy effect of PW and PS occurred.

\section{References}

1. Lee MS, Back SC, Kang CG (2012) Investigation of thin boron steel sheet formability in hot deep drawing processes according to process parameters. J Eng Manufac 226:898-908

2. Casas B, Latre D, Rodríguez N, Valls I (2008) Tailor made tool materials for the present and upcoming tooling solutions in hot sheet metal forming. In: Proceedings of 1st International conference on hot sheet metal forming of high-performance steel. Kassel, Germany

3. Liang Y, Xi Z, Minghua D, Sizhu Z, Ping H (2016) Crashworthiness design of quenched boron steel thin-walled structures with functionally graded strength. Int J Impact Eng 95:72-88 
4. Marklund PO, Nilsson L (2001) Optimization of a car body component subjected to side impact. Struct Multidiscip Optim 21:383-392

5. Munera D, Lacassin L, Pinard F (2007) Very and ultra high strength steels based tailored blanks: a step further towards vehicle crash performance improvement. Rev Metallurgie 104:613-624

6. Ma N, Hu P, Zhang Z (2011) Research on Tailored Microstructure Meterial in Hot Forming and its Application. In: Proceedings of 3rd international conference on hot sheet metal forming of highperformance steel. Kassel, Germany

7. Liu Y, Zhu Z, Wang Z, Zhu B, Wang Y, Zhang Y (2017) Formability and lubrication of a B-pillar in hot stamping with 6061 and 7075 aluminum alloy sheets. International Conference on the Technology of Plasticity 207:723-728

8. Morteze K, Imtiaz G, Masoud RR, Keiichi M (2014) Design of lightweight magnesium car body structure under crash and vibration constraints. J Magnesium and Alloys 2:99-108

9. Lee MS, Seo HY, Kang CG (2016) Comparative study on mechanical properties of CR340/CFRP composites through three point bending test by using theoretical and experimental methods. Int $\mathrm{J}$ Precision Eng and Manufac-Green Technology 3:359-365

10. Onur C, Oktay C, Ahmet G, Ugur U, Hakan A, Ahmet G (2020) Microstructural features and mechanical properties of 22MnB5 hot stamping steel in different heat treatment conditions. J of Mater Research and Tech 9:10901-10908

11. Merklein M, Johannes M, Lechner M (2014) A review on tailored blanks production applications and evaluation. J Mater Process Technol 214:151-164.

12. Lamprecht K, Geiger M (2005) Experimental and numerical investigation of the formability of laser welded patchwork blanks. Adv Mater Res 6:689-696

13. Lamprecht K, Geiger M (2005) Characterisation of the forming behaviour of patchwork blanks. Steel research int 76:910-915

14. Ahmad MA, Zakaria A (2014) Optimization of Spot Welds on Patchwork Blank for Hot Forming Process. Appl Mech Mater 606:177-180 
15. Chengxi L, Zhongwen X, Weili X (2017) Hot stamping of patchwork blanks: modelling and experimental investigation. Int J Adv Manuf Technol 92:2609-2617

16. Banik J, Lenze FJ, Sikora S (2011) Tailored properties -a pivotal question for hot forming. In: Proceedings of 2nd international conference on hot sheet metal forming. Lulea, Sweden

17. Ota E, Yogo Y, Iwata N (2019) CAE-based process design for improving formability in hot stamping with partial cooling. J Mater Process Technol 263:198-206

18. Bok HH, Choi JW, Suh DW (2015) Stress development and shape change during press-hardening process using phase-transformation-based finite element analysis. Int J Plast 73:142-170

19. Kim DK, Woo YY, Park KS (2018) Advanced induction heating system for hot stamping. Int J Advanced Manufac Technol 99:583-593

20. Lee MS, Lim OD, Kang CG, Moon YH (2020) Combined application of patchwork and partial softening to enhance the collision resistance of the center pillar. Int $\mathrm{J}$ Crashworthiness. https://doi.org/10.1080/13588265.2020.1836881

21. Side impact crashworthiness evaluation (version X); Insurance Institute for Highway Safety, 2017,.

22. Yin H, Xiao Y, Wen G (2015) Multi objective Optimisation for Foam-Filled Multi-Cell Thin-Walled Structures Under Lateral Impact. Thin-Walled Struct 94:1-12

23. https://en.wikipedia.org/wiki/Kronecker_delta

24. Dunne F, Nik P (2005) Introduction to computational plasticity. Oxford univ. press on demand, United Kingdom

25. Abaqus User's Manual 6.11 (2010). URL: http://130.149.89.49:2080/v6.11/pdf_books/CAE.pdf

26. Ciulia V, Sterfania B, Andrea G, Xiao C (2019) Numerical modeling of the 22MnB5 formability at high temperature. 18th Int Conf on Sheet Metal (SHEMET 2019) 29:428-434.

27. IIHS Side Impact Test Program Rating Guidelines (2016) Insurance Institute for Highway Safety.

28. First side impact tests (2003) : How 12 small SUVs fared; Insurance Institute for Highway Safety

29. Side Impact Crashworthiness Evaluation (2016); Crash Test Protocol (Version IX); Insurance Institute for Highway Safety 


\section{Author contributions}

Methodology, M.S.L; writing-original draft, M.S.L; writing review and editing, M.S.L, C.K.J, O.D.L and J.H.S; software, M.S.L; formal analysis, M.S.L and C.K.J; investigation, O.D.L and M.S.L; funding, J.H. S; validation and supervision, J.H.S; All authors have read and agreed to the published version of the manuscript.

\section{Acknowledgements}

This research was supported by Basic Science Research Program through the National Research Foundation of Korea (NRF) funded by the Ministry of Science, ICT \& Future Planning (No. 2021R1C1C201276311) (No. 2020M3H4A3106186).

\section{Data availability}

The datasets generated during and/or analyzed during the current study are available from the corresponding author on reasonable request

\section{Declarations}

Ethical approval The authors claim that none of the contents in this manuscript has been published or considered for publication elsewhere. Besides, the research contents of the article do not violate ethics.

Consent to participate This manuscript does not involve human or animal participation or data; therefore, consent to participate is not applicable.

Consent for publication This manuscript does not contain data from any individual person; therefore, consent to publish is not applicable. 
Competing interests The authors declare no competing interests. 